\title{
Long noncoding RNA: its partners and their roles in cancer
}

\author{
Minireview
}

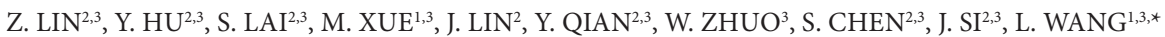

${ }^{1}$ Department of Gastroenterology, the Second Affiliated Hospital, School of Medicine, Zhejiang University, Hangzhou 310009, China; ${ }^{2}$ Department of Gastroenterology, Sir Runrun Shaw Hospital, School of Medicine, Zhejiang University, Hangzhou 310003, China; ${ }^{3}$ Institute of Gastroenterology, Zhejiang University, Hangzhou 310016, China

${ }^{*}$ Correspondence: wanglj76@hotmail.com

Received April 16, 2015 / Accepted July 16, 2015

RNA transcripts, which do not encode proteins, have received considerable attention in recent years. These non-coding RNAs are classified into two groups: small non-coding RNAs and long non-coding RNAs (lncRNAs). Increasing evidence suggests that lncRNAs are emerging as key regulators in many biological processes. However, knowledge of the underlying mechanisms whereby they act is still limited. Here, we try to elucidate the way that lncRNAs function in the context of DNA, RNA and protein interaction networks. It is noteworthy that lncRNA and another type of non-coding RNA microRNA (miRNA) may 'talk' to each other more frequently than ever expected. Additionally, lncRNAs display aberrant expression profiles in different kinds of cancers, with their potential roles in carcinogenesis and cancer metastasis. We summarize the effect of some cancer related lncRNAs upon tumor biological events, including cell proliferation, apoptosis, invasion and metastasis. Finally, we focus on the clinical value of lncRNAs, considering their potential application in cancer diagnosis, prognosis and therapeutic intervention.

Key words: long noncoding RNA, microRNA, RNA interaction network, cancer, metastasis

The Encyclopedia of DNA Elements (ENCODE) project has found that three-quarters of the human genome are capable of transcription, while less than $2 \%$ of them is translated into proteins [1]. Most protein coding genes have been frequently studied. However, a new development in genomic research may be the shift from studying exclusively the protein coding components of the genome to consideration of the roles of regulatory noncoding parts. According to their transcript size, these noncoding RNAs can be grouped into two classes: small noncoding RNAs ( $<200 \mathrm{bp})$, such as miRNA, piRNA, etc. and long noncoding RNAs (lncRNAs) (> 200bp). Compared

Abbreviations: lncRNA - long non-coding RNA; miRNA - microRNA; H3K4me3 - histone H3 lysine 4 trimethylation; H3K36me3 - histone H3 lysine 36 trimethylation; RIP - RNA-immunoprecipitation; ChRIP - chromatin RNA immunoprecipitation; lincRNA - long intergenic noncoding RNA; PRC2 - Polycomb repressive complex 2; AS - Alternative splicing; CCND1 - Cyclin D1; hnRNP-K - heterogeneous nuclear ribonucleoprotein K; ceRNA - competitive endogenous RNA; MREs - microRNA response elements; EMT - epithelial-mesenchymal transition; HCC - Hepatocellular carcinoma; PSA - prostate-specific antigen; OSCC - oesophageal squamous cell carcinoma; ASOs - Antisense oligonucleotides to the former, long noncoding RNAs are less documented. Once considered nonsense, they are now recognized as key regulators in many biological processes, including parental imprinting [2], derivation of pluripotent stem cells [3] and somatic tissue differentiation [4].

Recently, the relevance of $\operatorname{lncRNAs}$ to diseases, such as neural disorders [5], immunological diseases [6], respiratory diseases [7] and cancer draws people's attention. Dysregulation of IncRNAs occurs in a variety of cancers. Recent studies demonstrate that lncRNAs play vital roles in carcinogenesis and cancer metastasis. The advancement in technology, including the tiling microarray and RNA-seq [8], drives the mapping of lncRNAs to an unprecedented degree. A very small percentage of lncRNAs, such as XIST, H19 and HOTAIR, have been well studied and the molecular mechanisms are clarified. In contrast to these substantial progresses, the functional roles for the overwhelming majority of lncRNAs remain elusive. In this review, we summarize the mechanisms through which lncRNAs function in the genetic interaction network. The interaction between lncRNAs and the development and progression of cancer was systemically reviewed and the discovered roles 
of lncRNAs were potentially proposed in the diagnosis and treatment of cancers.

The identification of IncRNAs. Long noncoding RNAs are identified as RNA transcripts larger than 200 nucleotides (nt) without an open reading frame that encodes a functional protein [9]. They are often transcribed by RNA polymerase II. Localized in the nucleus or cytoplasm, they may be polyadenylated or not, 5 'caps, and may be processed into small RNAs [10]. They are generally lower expressed than protein-coding genes, and display certain tissue-specific expression patterns [11]. Based on its genomic distribution, lncRNAs can be classified into five categories: sense, antisense, bidirectional, intronic, and intergenic [9].

By utilizing technologies including tiling microarrays [12], RNA sequencing $[8,13]$ and transcript abundance estimations, which allow the first step toward characterizing $\ln$ cRNA, studies have identified specific properties of distinct classes of IncRNA genes. These technologies combined with numerous annotation sources also give chance to unveil the genome-wide lncRNA expression signatures of various types of cancers. Another way to identify lncRNAs is chromatin-state map. Since the chromatinmodification landscape of mammalian genomes was depicted [14], a clear signature was found relative to active transcription recently. The signature contains a short stretch of histone $\mathrm{H} 3$ lysine 4 trimethylation ( $\mathrm{H} 3 \mathrm{~K} 4 \mathrm{me} 3)$, and a following longer stretch of histone $\mathrm{H} 3$ lysine 36 trimethylation (H3K36me3), termed "K4-K36 domain". By identifying K4-K36 domains that lie outside of known protein-coding gene loci, Guttman and his colleagues revealed more than a thousand lncRNAs that show a high degree of evolutionary conservation, implying their potential biological functions [10]. The methods to explore the molecular mechanisms of $\ln$ cRNAs have been reviewed by Kung et al [15], including RNA-immunoprecipitation (RIP) and chromatin RNA immunoprecipitation (ChRIP). An expanding list of up-to-date technologies may help to elucidate the great diversity in the structures and functions of $\operatorname{lncRNAs}$, but there is still a long way to go.

The interaction network of lncRNAs and its partners. The genomic regulation network of eukaryotic genome is very intricate which contains specific and dynamic interactions between RNA species and DNA or proteins. Emerging evidence shows that lncRNAs are indispensable in this network. The molecular mechanisms of lncRNAs could be described as four main models: Signals, Decoys, Guides, Scaffolds [16]. The four archetypes cover functional mechanisms of most known lncRNAs. In this review, we highlight the interactions of IncRNA with DNA, RNA and protein molecules in the regulatory network, in the hope of providing clues to future researches (Fig 1.).

Interaction with DNAs. As a major component of the 'central dogma', DNA molecules constitute the human genome with enormous genetic information. Recently, a noncoding RNA was indicated to be able to interact with the promoter of rDNA (rRNA genes) by forming a DNA: RNA triplex with the T0 (oligo \#4) sequence [17]. The potential role of the triplex as form of RNA:
DNA interaction, and whether lncRNA could bind to DNA sequence via similar structure are still unclear. Comprehensive surveys demonstrated that human genome is pervasively transcribed. Many noncoding transcripts have been identified and the majority of them overlap with protein-coding loci [18], which providing a possible hint of IncRNA-DNA interaction.

A Gene Ontology (GO) analysis discovered the connection of one coding gene to at least three lncRNAs and that of one lncRNA to at least three coding genes [19]. Considering the influence of lncRNAs on gene expression, even though the majority of interactions are indirect, the data provides profound insight into genetic regulatory network. For instance, a $17 \mathrm{~kb} \mathrm{X}$-inactive-specific transcript (XIST/Xist), one of the first lncRNAs discovered in mammals [20], is expressed exclusively in the inactive $\mathrm{X}$ chromosome (Xi). Accumulation of Xist RNA has been observed near its transcriptional site, $\mathrm{Xi}$ and the loading of Xist onto $\mathrm{Xi}$ induces the inactivation of $\mathrm{X}$ chromosome [2].

Interaction with proteins. Numerous examples show that specific proteins could interact with $\ln c$ RNAs to facilitate their modulatory effects. These protein partners may be intranuclear or cytoplasmic and comprise participants in pervasive cellular processes, varying from the epigenetic modification of chromatin gene transcriptional regulation to alternative splicing.

Chromatin-modifying complexes. It has become a major theme of lncRNA biology that some lncRNAs are capable of recruiting protein molecules for regulation of chromatin status. Approximately $20 \%$ of the mammalian genome encoded long intergenic noncoding RNAs (lincRNAs) were observed to physically associate with chromatin-modifying complexes [21]. HOTAIR, which is transcribed from the HOXC locus on chromosome 12q13.13, has been demonstrated to work as modular scaffold of two different chromatin modification complexes [13]. The 5' domain of HOTAIR binds to PRC2 (Polycomb repressive complex 2), whereas the 3 ' domain binds to the LSD1/CoREST/REST complex. LSD1 is a histone lysine demethylase, responsible for demethylation of H3K4Me2. By guiding PRC2 or LSD1 to target genes, HOTAIR represses transcription in trans of the HOXD locus located on chromosome 2. Similarities are shown in ANRIL $[22,23]$ and TUG1 [24]. Other histone modification regulators, such as the H3K9 methyltransferase G9a, which would interact with the imprinted lncRNA Air, were also reported. LncRNAs can work as both in-trans and in-cis regulators of gene expression through RNA-protein interaction [25].

pre-mRNA splicing factors. Alternative splicing (AS) is a key step in the generation of RNA diversity and the regulation of gene function [26]. A study using RNA-IP followed by RT-PCR revealed the interaction between MALAT1 (metastasisassociated lung adenocarcinoma transcript 1 ) and several splicing factors- SRSF1, SRSF2, and SRSF3. MALAT1, an abundant nuclear-retained lncRNA, can bind to SR proteins with its 5' end and modulate AS of endogenous pre-mRNAs by regulating the distribution and phosphorylation of SR proteins [27]. Further studies proposed that MALAT1 influence 


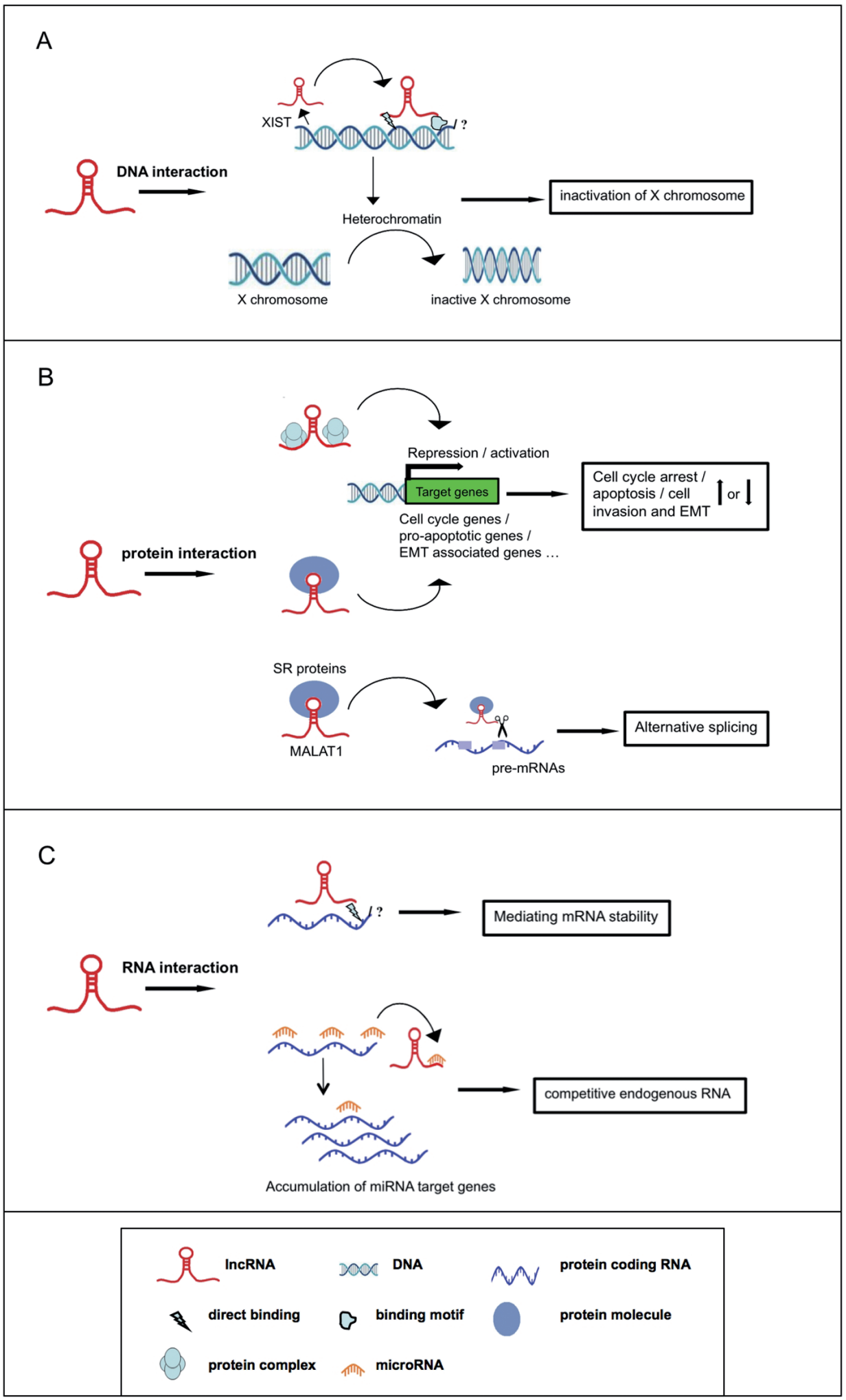

Figure 1. The interactions of IncRNA with DNA, RNA and protein molecules in the regulatory network A. Specific lncRNAs could interact with DNA directly or through binding motifs and lead to chromatin remodeling, such as Xist. B. IncRNA transcripts could bind to protein molecules or serve as scaffold of protein complexes and activate or repress the transcription of specific target genes by directing the location of functional proteins. By bind to SR proteins, IncRNA can also affect RNA processing, such as MALAT1. C. IncRNAs can interplay with mRNAs and mediate their stability by direct binding or unknown mechanisms. Other IncRNAs titrate away small regulatory RNAs, such as miRNA, and serve as competitive endogenous RNA. 
the expression of a transcription regulator B-MYB, which in turn resulted in altering transcription of downstream genes [28]. Thus, the interaction of MALAT1 and specific splicing factors contributes to its role in hyper-proliferation and metastasis of cancer.

Other transcriptional regulators. Several lncRNAs within gene regulatory elements have been implicated in transcriptional regulation. NcRNA-CCDN1, a signal induced lncRNA transcribed from the 5'regulatory region of Cyclin D1 (CCND1) can recruit TLS (for translocated in liposarcoma) to CCND1 gene, resulting in the repression of transcription [29]. A p53-induced lncRNA that lies upstream of cell-cycle gene p21, PANDA (P21 associated ncRNA DNA damage activated), was validated to interact with the transcription factor NF-YA to prevent activation of pro-apoptotic genes, such as CCNB1, FAS, BBC3 and PMAIP1 [30]. Another promoter IncRNA, lincRNA-p21 ( 15 Kb upstream of $\mathrm{p} 21$ ), exerts its transcriptional repression effect through interaction with heterogeneous nuclear ribonucleoprotein $\mathrm{K}$ (hnRNP-K) [31]. These findings suggest the potential roles of lncRNAs in cell-growth control. More broadly, by interacting with transcription factors or co-regulators, lncRNAs near or within protein coding genes may have functional activities in specific cellular processes, which might provide a promising way to detect novel lncRNAs and their functions.

Similar to the transcription of protein-coding genes, some transcription regulators bind to the promoter region of lncRNA genes and influence the expression of lncRNAs. Transcription factor c-Myc could directly bind to the E-box element in the promoter region of lncRNA CCAT1, and facilitate the expression of CCAT1 [32]. By binding to the promoter of one $\mathrm{H} 19$ allele, c-Myc also significantly increases the expression level of the H19 noncoding RNA [33].

Interaction with RNAs. RNA-RNA interactions provide one of the fundamental mechanisms of the genetic regulatory networks. Emerging evidence suggests that lncRNAs work with other RNA molecules, such as mRNA and microRNA. However, by now whether other components in the RNA world can interact with lncRNA remains unclear.

$m R N A$. LncRNAs may involve in the post-transcriptional gene regulation through interaction with associated mRNA. An exemplary study revealed that a cytoplasmic lncRNA TINCR (terminal differentiation-induced ncRNA) interacts with a great range of differentiation $\mathrm{mRNAs}$ through genome-scale RNA interactome analysis. The TINCR-mRNA interaction occurs when a 25-nucleotide 'TINCR box' motif exists. By binding to differentiation $\mathrm{mRNAs}$ and mediating their stability, TINCR controls human epidermal differentiation post-transcriptionally [34]. A similar example is lincRNA-p21, whose stability could be reduced by a RNA-binding protein HuR. Several high complementary regions of lincRNA-p21 were identified for CTNNB1 mRNA (15 sites) and JUNB mRNA (8 sites) when compared to GAPDH mRNA (2 sites), supporting the selective lncRNA-mRNA interaction [35].
microRNA. MicroRNAs (miRNAs), approximately $23 \mathrm{nt}$ in length, are a large class of noncoding, endogenous, small ncRNAs, which have emerged as a critical element in gene regulation. By pairing to messenger RNA of protein coding genes, miRNAs induce post-transcriptional repression of target mRNAs [36]. LncRNAs may serve as 'microRNA sponge' or 'competitive endogenous RNA (ceRNA)' and impart diverse functions to the cryptic transcriptome.

Franco-Zorrilla et al [37] indicated that a lncRNA IPS1 (induced by phosphate starvation 1) from Arabidopsis thaliana contains a motif with sequence complementary to miRNA, and coin the term 'target mimicry' to define this mechanism of inhibition of miRNA activity. Wang et al [38] discovered the auto-regulatory loop of lncRNA highly upregulated in liver cancer (HULC) via interaction with miRNA-372, similar to the mechanism of 'target mimicry'. However, this is only a tiny tip of the iceberg in the RNA-RNA interaction network. Accumulating evidence support that the two classes of regulatory RNA, lncRNAs and microRNA, may correlate with each other even more frequently. Recently, a hypothesis that different types of RNAs 'talk' to each other through a new 'language' mediated by microRNA response elements (MREs), was proposed by Pandolfi et al [39]. By competing for a limited reservoir of microRNAs, various RNA transcripts may influence each other's expression levels. This 'competing endogenous RNA' activity, including lncRNAs as one of 'the ceRNA protagonists', implicates a brand new large-scale regulatory network.

Supporting the hypothesis, PTENP1 [40], a noncoding pseudogene, is revealed to be able to reduce the repression of both PTEN transcript and protein by binding miRNAs. PTEN and its related pseudogene PTENP1 (highly homologous to PTEN) share many conserved MREs. A similar relationship can be detected in another gene-pseudogene partner, KRAS and its pseudogene KRAS1P [40]. In addition to genepseudogene partners, long ncRNAs may play ceRNAs roles to influence a large scale of gene expression. A cytoplasmic lncRNA, linc-MD1, can decoy miR-133 and miR-135 to regulate the expression of MAML1 and MEF2C respectively [4]. On the other hand, miRNAs may target lncRNA transcripts and negatively regulate lncRNA, which resembles the miRNAmediated silencing of target mRNAs [41]. Taken together, lncRNA-miRNA interactions expand the genetic regulatory networks to a large extent. Table 1 displays updated information of public databases of lncRNAs, including their interaction with RNA and protein.

The roles of lncRNAs in carcinogenesis and cancer metastasis. Although the study of lncRNAs involved in cancer biology is still in its infancy, a handful of lncRNAs have been shown to be associated with hallmarks of cancer. lncRNAs may affect many tumor biological events including cell cycle, apoptosis, cancer-related signaling pathways, invasion and metastasis, showing dual characteristics in cancer development (Fig 2.). Here, we display some well-documented lncRNAs with oncogenic or tumor suppressive property in Table2. 


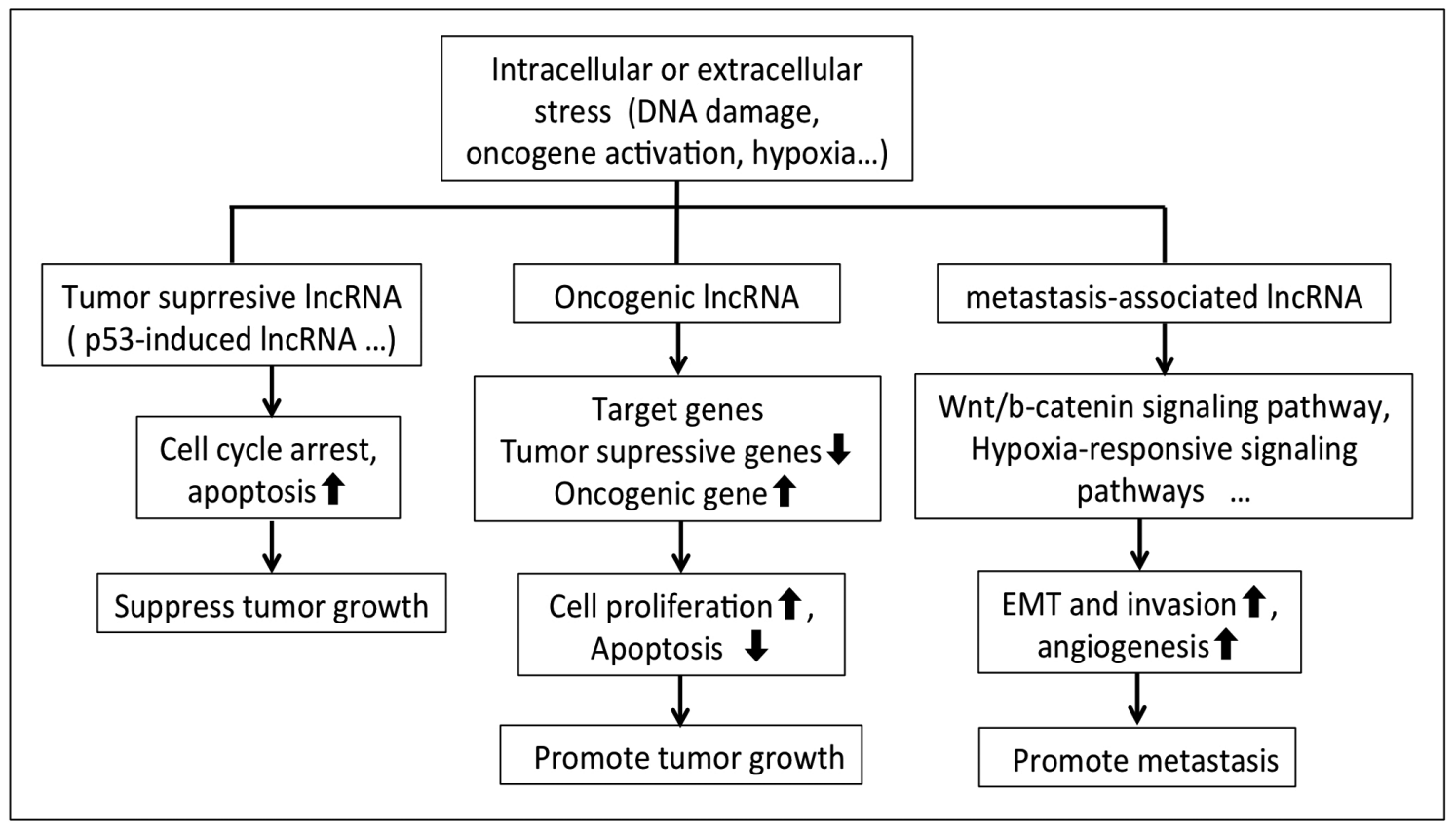

Figure 2. The roles of lncRNA in carcinogenesis and metastasis lncRNAs exert complicated functions in cancer. Under multiple stresses, tumor suppressive or oncogenic lncRNAs and metastasis-associated lncRNAs are induced to influence tumor growth or metastasis.

Cell proliferation and apoptosis. In the attempt to probe into the lncRNA involvement in cell-cycle regulation, some lncRNAs were identified near or within cell-cycle genes. Under multiple cell stress (DNA damage, oncogene activation, hypoxia), p53 will activate the transcription of target genes, including PANDA and lincRNA-p21 [30, 31]. The lncRNAs involved in p53 pathway may be much more than ever expected. For example, LncRNA loc285194, also termed LSAMP antisense RNA 3, has been shown to inhibit tumor cell growth and identified as a p53-induced lncRNA [35]. Evidence showed that lncRNA GAS5 exerts a tumor suppressive function in carcinogenesis with its the regulatory role on apoptosis [42]. Conversely, several other lncRNAs have been reported to promote cell growth and displayed oncogenic properties in prostate cancer, including PCGEM1 (prostatespecific transcript 1) [43], PCAT-1 [44], PRNCR1 (prostate cancer noncoding RNA 1) [45], PlncRNA-1 [46] and PCA3 [47]. These researches uncover an important phenomenon that lncRNAs can play both positive and negative roles in cell life/death control.

Cancer metastasis. As key hallmarks of cancer, invasion and metastasis-spread of cancer cells to adjacent tissues or distant organs, are deemed as a major cause of cancer-related death and disease status [48]. Recently, differential expression pattern of a set of lncRNAs was found in primary and metastatic pancreatic cancer, suggesting that lncRNAs may participate in metastasis [49].

HOTAIR and MALAT-1 are the most well-documented lncRNAs that have been reported to play critical roles in invasion and metastasis. Gupta et al [50] found that HOTAIR was dysregulated in breast cancer and had prognostic value for metastasis and survival. Their findings suggested that

Table 1. Updated public databases of IncRNAs

\begin{tabular}{lllll}
\hline Name & Website & Specialty & Refs. \\
\hline NONCODEv4 & http://www.bioinfo.org/noncode/ & a integrated knowledge database of noncoding RNAs & [63] \\
LNCipedia 3.0 & http://www.lncipedia.org & a comprehensive annotation of human lncRNA sequences & [64] \\
lncRNAdb v2.0 & http://lncrnadb.org & a database for functional long noncoding RNAs & [65] \\
starBase v2.0 & http://starbase.sysu.edu.cn/ & decoding the RNA-RNA and protein-RNA interaction networks from CLIP-Seq data & [66] & [67] \\
DIANA-LncBase & www.microrna.gr/LncBase & a database of miRNA-lncRNA putative functional interactions & [68] \\
LncRNADisease & http://cmbi.bjmu.edu.cn/lncrnadisease & a collection of experimentally supported and predicted lncRNA-disease associations & [69] \\
lncRNASNP & http://bioinfo.life.hust.edu.cn/lncRNASNP/ & a database of disease-associated SNPs in lncRNAs & \\
\hline
\end{tabular}

Abbreviations: CLIP-Seq, high-throughput sequencing of immunoprecipitated RNAs after cross-linking; SNPs, single nucleotide polymorphisms 
Table 2. IncRNAs with oncogenic or tumor suppressive property

\begin{tabular}{|c|c|c|c|c|c|c|}
\hline LncRNA & $\begin{array}{l}\text { Expression } \\
\text { level }\end{array}$ & Cancer types & Property & Molecular interaction & $\begin{array}{l}\text { Subcellular lo- } \\
\text { calization }\end{array}$ & Refs. \\
\hline ANRIL/p15AS & Low & Prostate cancer, leukemia & Oncogenic & PCR1 and PCR2 & Nucleus & {$[23]$} \\
\hline HOTAIR & High & Breast cancer, liver cancer, and GIST & Oncogenic & PCR2 and LSD1 & Nucleus & {$[13]$} \\
\hline HULC & High & Liver cancer & Oncogenic & $\operatorname{miR}-372$ & Cytoplasm & {$[38]$} \\
\hline MALAT1/NEAT2 & High & NSCLC & Oncogenic & SR proteins & Nucleus & {$[27]$} \\
\hline PCA3 & High & Prostate cancer & Oncogenic & Unknown & Nucleus, cytoplasm & {$[47]$} \\
\hline PCAT-1 & High & Prostate cancer, colorectal cancer & Oncogenic & PCR2 & Nucleus & {$[44]$} \\
\hline UCA1 & High & Bladder cancer & Oncogenic & Unknown & Cytoplasm & {$[57,70]$} \\
\hline GAS5 & Low & Breast cancer & Tumor suppressive & GR & Cytoplasm & {$[42][71]$} \\
\hline MEG3 & Low & $\begin{array}{l}\text { Pituitary tumors, meningioma, } \\
\text { HCC, leukemia }\end{array}$ & Tumor suppressive & Unknown & Unknown & {$[72]$} \\
\hline PTENP1 & Low & Prostate cancer & Tumor suppressive & PTEN-targeting miRNAs & Cytoplasm & {$[40]$} \\
\hline lincRNA-p21 & Low & Various tumors & Tumor suppressive & hnRNP-K & Cytoplasm & {$[31,73]$} \\
\hline
\end{tabular}

Abbreviations: PCA3, prostate cancer antigen 3; PCAT-1, prostate cancer associated transcript-1; UCA1, urothelial carcinoma associated 1; GAS5, growth arrest-specific transcript 5; MEG3, maternally expressed gene 3; NSCLC, non-small-cell lung cancer; HCC, hepatocellular carcinoma; GR, Glucocorticoid Receptor.

HOTAIR was involved in the late event of cancer biology. MALAT-1, just as its name implies, was originally identified in 2003 to be a risk factor of lung cancer metastasis [51]. Two alternative mechanisms have been proposed for MALAT-1: alternative splicing and gene expression. In lung cancer, it is not alternative splicing but active regulation of gene expression containing a set of metastasis-associated genes that contributes to metastasis [52].

Multiple cellular events contribute to cancer invasion and metastasis, including a developmental regulatory program, known as 'epithelial-mesenchymal transition' (EMT). Recently, noncoding RNAs have been shown to play critical roles in EMT. For example, lncRNA-ATB (the lncRNA-activated by TGF- $\beta$ ), associated with HCC (Hepatocellular carcinoma) metastasis, was found to induce EMT and invasion [53]. Although limited lncRNAs were shown to be molecular regulators in metastasis-associated signaling, including the Wnt/b-catenin signaling pathway [54] and hypoxia-responsive signaling pathways [55], it provides important hints for further exploiting of other cancer-related lncRNAs.

The diagnostic and therapeutic value of lncRNAs in cancers. With the emerging recognition that lncRNAs are key components in genetic regulation and cancer development, it is expected that lncRNAs may act as potential biomarkers for diagnosis or prognosis and novel therapeutic targets.

A list of lncRNAs have been shown different expression patterns between tumor and normal tissues, a few of which were found closely associated with tumorigenesis or metastasis. Importantly, lncRNAs may also be detected in human fluids, such as blood and urine samples. For example, lncRNA PCA3 is utilized in urine test as a biomarker of prostate cancer for early detection [56]. In addition to the advantage of easy-get specimen, PCA3 also showed a higher specificity compared with current biomarker, prostate-specific antigen
(PSA). UCA1 is sensitive and specific urine biomarker for bladder cancer [57]. Highly expressed in HCC patients, lncRNA HULC could be detected in peripheral blood cells from HCC patients. Thus, a potential use of HULC as a prognostic biomarker in HCC can be envisaged [58]. LncRNAs may also have the potential to predict survival of patients with cancer. Jiagen Li et al [59] identified a three-lncRNA signature as a biomarker for the prognosis of patients with oesophageal squamous cell carcinoma (OSCC). Because of the limited accessibility of tissue samples, it is still far from clinical application of such $\operatorname{lncRNAs}$ as biomarkers according to the aberrant expression in tissues or samples.

LncRNAs also have the potential to be utilized as novel therapeutic targets. IncRNAs may be targeted with synthetic small RNA molecules, which could be used to selectively silence oncogenic lncRNAs. A study showed that silencing of IncRNA by shRNA reduced the resistance to chemotherapy drugs of bladder cancer cells [60]. Another example indicated that siRNA-mediated suppression of HOTAIR increased the response of liver cancer cell lines to chemotherapy drug cisplatin and doxorubicin [61]. A profound work demonstrated that systemic administration of siRNA with a targeted delivery system was able to produce a specific gene inhibition both in the mRNA and protein level [62]. However, for successful clinical application of lncRNA-based approaches, improvement should be made in developing more specific delivery systems or other techniques, together with more safety considerations. Since the secondary structure of IncRNAs is quite complicated, it's still a challenge to design siRNAs targeting lncRNA. In addition, as many lncRNAs function through interaction with other molecular partners, therapeutic options by preventing their interaction can be feasible. Disrupting the combination between PRC2 and HOTAIR, for instance, may incapacitate the loading of PCR2 on chromatin, thus decreasing the 
metastatic potential of cancer. It is already available to utilize oligonucleotides that bind and disrupt RNA-protein interactions. Gutschner et al [52] proposed that targeting MALAT1 with ASOs (Antisense oligonucleotides) might be a potential therapeutic strategy for lung cancer metastasis. Collectively, though most studies about the lncRNA-based targeted therapy remain in the preliminary stage, clinical translation of lncRNAs may provide promising strategies for clinical oncology.

Acknowledgements: This work was supported by grants from the National Natural Science Foundation of China (81302070, 81372623 and 81472214 ), the Zhejiang province key science and technology innovation team (2013TD13).

\section{References}

[1] DJEBALI S, DAVIS CA, MERKEL A, DOBIN A, LASSMANN $\mathrm{T}$ et al. Landscape of transcription in human cells. Nature. 2012; 489(7414): 101-108. http://dx.doi.org/10.1038/nature 11233

[2] CLEMSON CM, MCNEIL JA, WILLARD HF, LAWRENCE JB. XIST RNA paints the inactive X chromosome at interphase: Evidence for a novel RNA involved in nuclear chromosome structure. J Cell Biol. 1996; 132(3): 259-275. http://dx.doi.org/10.1083/jcb.132.3.259

[3] LOEWER S, CABILI MN, GUTTMAN M, LOH YH, THOMAS $\mathrm{K}$ et al. Large intergenic non-coding RNA-RoR modulates reprogramming of human induced pluripotent stem cells. Nature Genetics. 2010; 42(12): 1113-+. doi: Doi 10.1038/Ng.710.

[4] CESANA M, CACCHIARELLI D, LEGNINI I, SANTINI T, STHANDIER O et al. A long noncoding RNA controls muscle differentiation by functioning as a competing endogenous RNA. Cell. 2011; 147(2): 358-369. http://dx.doi.org/10.1016/j. cell.2011.09.028

[5] FAGHIHI MA, MODARRESI F, KHALIL AM, WOOD DE, SAHAGAN BG et al. Expression of a noncoding RNA is elevated in Alzheimer's disease and drives rapid feed-forward regulation of beta-secretase. Nat Med. 2008; 14: 723-730. http://dx.doi.org/10.1038/nm1784

[6] LIU ZH, LEE J, KRUMMEY S, LU W, CAI HB et al. The kinase LRRK2 is a regulator of the transcription factor NFAT that modulates the severity of inflammatory bowel disease. Nat Immunol. 2011; 12: 1063-U1065. http://dx.doi.org/10.1038/ $\underline{\text { ni. } 2113}$

[7] BOOTON R, LINDSAY MA. Emerging Role of MicroRNAs and Long Noncoding RNAs in Respiratory Disease. Chest. 2014; 146: 193-204. http://dx.doi.org/10.1378/chest.13$\underline{2736}$

[8] MORTAZAVI A, WILLIAMS BA, MCCUE K, SCHAEFFER L, WOLD B. Mapping and quantifying mammalian transcriptomes by RNA-Seq. Nature Methods. 2008; 5: 621-628. http:// dx.doi.org/10.1038/nmeth.1226

[9] PONTING CP, OLIVER PL, REIK W. Evolution and functions of long noncoding RNAs. Cell. 2009; 136: 629-641. http:// dx.doi.org/10.1016/j.cell.2009.02.006
[10] GUTTMAN M, AMIT I, GARBER M, FRENCH C, LIN MF et al. Chromatin signature reveals over a thousand highly conserved large non-coding RNAs in mammals. Nature. 2009; 458: 223-227. http://dx.doi.org/10.1038/nature07672

[11] DERRIEN T, JOHNSON R, BUSSOTTI G, TANZER A, DJEBALI $S$ et al. The GENCODE v7 catalog of human long noncoding RNAs: Analysis of their gene structure, evolution, and expression. Genome Res. 2012; 22: 1775-1789. http:// dx.doi.org/10.1101/gr.132159.111

[12] BERTONE P, STOLC V, ROYCE TE, ROZOWSKY JS, URBAN AE et al. Global identification of human transcribed sequences with genome tiling arrays. Science. 2004; 306: 2242-2246. http://dx.doi.org/10.1126/science.1103388

[13] TSAI MC, MANOR O, WAN Y, MOSAMMAPARAST N, WANG JK et al. Long noncoding RNA as modular scaffold of histone modification complexes. Science. 2010; 329: 689-693. http://dx.doi.org/10.1126/science.1192002

[14] BARSKI A, CUDDAPAH S, CUI K, ROH TY, SCHONES DE et al. High-resolution profiling of histone methylations in the human genome. Cell. 2007; 129: 823-837. http://dx.doi. org/10.1016/j.cell.2007.05.009

[15] KUNG JT, COLOGNORI D, LEE JT. Long noncoding RNAs: past, present, and future. Genetics. 2013; 193: 651-669. http:// dx.doi.org/10.1534/genetics.112.146704

[16] WANG KC, CHANG HY. Molecular mechanisms of long noncoding RNAs. Molecular cell. 2011; 43: 904-914. http:// dx.doi.org/10.1016/j.molcel.2011.08.018

[17] SCHMITZ KM, MAYER C, POSTEPSKA A, GRUMMT I. Interaction of noncoding RNA with the rDNA promoter mediates recruitment of DNMT3b and silencing of rRNA genes. Genes \& development. 2010; 24: 2264-2269. http:// dx.doi.org/10.1101/gad.590910

[18] CONSORTIUM EP, BIRNEY E, STAMATOYANNOPOULOS JA, DUTTA A, GUIGO R et al. Identification and analysis of functional elements in $1 \%$ of the human genome by the ENCODE pilot project. Nature. 2007; 447: 799-816. http://dx.doi.org/10.1038/nature05874

[19] YANG H, ZHONG Y, XIE H, LAI X, XU M et al. Induction of the liver cancer-down-regulated long noncoding RNA uc002mbe. 2 mediates trichostatin-induced apoptosis of liver cancer cells. Biochemical pharmacology. 2013; 85: 1761-1769. http://dx.doi.org/10.1016/j.bcp.2013.04.020

[20] BROWN CJ, HENDRICH BD, RUPERT JL, LAFRENIERE RG, XING Y et al. The human XIST gene: analysis of a $17 \mathrm{~kb}$ inactive X-specific RNA that contains conserved repeats and is highly localized within the nucleus. Cell. 1992; 71: 527-542. http://dx.doi.org/10.1016/0092-8674(92)90520-M

[21] KHALIL AM, GUTTMAN M, HUARTE M, GARBER M, RAJ A et al. Many human large intergenic noncoding RNAs associate with chromatin-modifying complexes and affect gene expression. P Natl Acad Sci USA. 2009; 106: 11667-11672. http://dx.doi.org/10.1073/pnas.0904715106

[22] YAP KL, LI SD, MUNOZ-CABELLO AM, RAGUZ S, ZENG $L$ et al. Molecular Interplay of the Noncoding RNA ANRIL and Methylated Histone H3 Lysine 27 by Polycomb CBX7 in Transcriptional Silencing of INK4a. Mol Cell. 2010; 38: 662-674. http://dx.doi.org/10.1016/j.molcel.2010.03.021 
[23] KOTAKE Y, NAKAGAWA T, KITAGAWA K, SUZUKI S, LIU $\mathrm{N}$ et al. Long non-coding RNA ANRIL is required for the PRC2 recruitment to and silencing of p15(INK4B) tumor suppressor gene. Oncogene. 2011; 30: 1956-1962. http://dx.doi. org/10.1038/onc. 2010.568

[24] ZHANG EB, YIN DD, SUN M, KONG R, LIU XH et al. P53-regulated long non-coding RNA TUG1 affects cell proliferation in human non-small cell lung cancer, partly through epigenetically regulating HOXB7 expression. Cell death \& disease. 2014; 5. doi: ARTN e1243

[25] SANDOVAL J, ESTELLER M. Cancer epigenomics: beyond genomics. Current Opinion in Genetics \& Development. 2012; 22: 50-55. http://dx.doi.org/10.1016/j.gde.2012.02.008

[26] BLENCOWE BJ. Alternative splicing: new insights from global analyses. Cell. 2006; 126: 37-47. http://dx.doi. org/10.1016/j.cell.2006.06.023

[27] TRIPATHI V, ELLIS JD, SHEN Z, SONG DY, PAN Q et al. The Nuclear-Retained Noncoding RNA MALAT1 Regulates Alternative Splicing by Modulating SR Splicing Factor Phosphorylation. Molecular Cell. 2010; 39: 925-938. http://dx.doi. org/10.1016/j.molcel.2010.08.011

[28] TRIPATHI V, SHEN Z, CHAKRABORTY A, GIRI S, FREIER $\mathrm{SM}$ et al. Long Noncoding RNA MALAT1 Controls Cell Cycle Progression by Regulating the Expression of Oncogenic Transcription Factor B-MYB. Plos Genet. 2013; 9. doi: Artn E1003368

[29] WANG XT, ARAI S, SONG XY, REICHART D, DU K et al. Induced ncRNAs allosterically modify RNA-binding proteins in cis to inhibit transcription. Nature. 2008; 454: 126-U111. http://dx.doi.org/10.1038/nature06992

[30] HUNG T, WANG Y, LIN MF, KOEGEL AK, KOTAKE Y et al. Extensive and coordinated transcription of noncoding RNAs within cell-cycle promoters. Nature genetics. 2011; 43: 621-629. http://dx.doi.org/10.1038/ng.848

[31] HUARTE M, GUTTMAN M, FELDSER D, GARBER M, KOZIOL MJ et al. A large intergenic noncoding RNA induced by $\mathrm{p} 53$ mediates global gene repression in the $\mathrm{p} 53$ response. Cell. 2010; 142: 409-419. http://dx.doi.org/10.1016/j. cell.2010.06.040

[32] YANG F, XUE XC, BI JW, ZHENG LM, ZHI KK et al. Long noncoding RNA CCAT1, which could be activated by c-Myc, promotes the progression of gastric carcinoma. J Cancer Res Clin. 2013; 139: 437-445. http://dx.doi.org/10.1007/s00432012-1324-X

[33] BARSYTE-LOVEJOY D, LAU SK, BOUTROS PC, KHOSRAVI F, JURISICA I et al. The c-Myc oncogene directly induces the $\mathrm{H} 19$ noncoding RNA by allele-specific binding to potentiate tumorigenesis. Cancer Res. 2006; 66: 5330-5337. http://dx.doi.org/10.1158/0008-5472.CAN-06-0037

[34] KRETZ M, SIPRASHVILI Z, CHU C, WEBSTER DE, ZEHNDER A et al. Control of somatic tissue differentiation by the long non-coding RNA TINCR. Nature. 2013; 493: 231-U245. http://dx.doi.org/10.1038/nature11661

[35] YOON JH, ABDELMOHSEN K, SRIKANTAN S, YANG $\mathrm{X}$, MARTINDALE JL et al. LincRNA-p21 suppresses target mRNA translation. Molecular cell. 2012; 47: 648-655. http:// dx.doi.org/10.1016/j.molcel.2012.06.027
[36] BARTEL DP. MicroRNAs: Target Recognition and Regulatory Functions. Cell. 2009; 136: 215-233. http://dx.doi. org/10.1016/j.cell.2009.01.002

[37] FRANCO-ZORRILLA JM, VALLI A, TODESCO M, MATEOS I, PUGA MI et al. Target mimicry provides a new mechanism for regulation of microRNA activity. Nature Genetics. 2007; 39: 1033-1037. http://dx.doi.org/10.1038/ng2079

[38] WANG JY, LIU XF, WU HC, NI PH, GU ZD et al. CREB upregulates long non-coding RNA, HULC expression through interaction with microRNA-372 in liver cancer. Nucleic Acids Res. 2010; 38: 5366-5383. http://dx.doi.org/10.1093/nar/ gkq285

[39] SALMENA L, POLISENO L, TAY Y, KATS L, PANDOLFI PP. A ceRNA hypothesis: the Rosetta Stone of a hidden RNA language? Cell. 2011; 146: 353-358. http://dx.doi.org/10.1016/j. cell.2011.07.014

[40] POLISENO L, SALMENA L, ZHANG JW, CARVER B, HAVEMAN WJ et al. A coding-independent function of gene and pseudogene mRNAs regulates tumour biology. Nature. 2010; 465: 1033-U1090. http://dx.doi.org/10.1038/nature09144

[41] ZHANG Z, ZHU Z, WATABE K, ZHANG X, BAI C et al. Negative regulation of lncRNA GAS5 by miR-21. Cell Death Differ. 2013; 20: 1558-1568. http://dx.doi.org/10.1038/ cdd.2013.110

[42] MOURTADA-MAARABOUNI M, PICKARD MR, HEDGE VL, FARZANEH F, WILLIAMS GT. GAS5, a non-proteincoding RNA, controls apoptosis and is downregulated in breast cancer. Oncogene. 2009; 28: 195-208. http://dx.doi. org/10.1038/onc.2008.373

[43] FU XQ, RAVINDRANATH L, TRAN N, PETROVICS G, SRIVASTAVA S. Regulation of apoptosis by a prostate-specific and prostate cancer-associated noncoding gene, PCGEM1. DNA Cell Biol. 2006; 25: 135-141. http://dx.doi.org/10.1089/ dna.2006.25.135

[44] PRENSNER JR, IYER MK, BALBIN OA, DHANASEKARAN $\mathrm{SM}, \mathrm{CAO} \mathrm{Q}$ et al. Transcriptome sequencing across a prostate cancer cohort identifies PCAT-1, an unannotated lincRNA implicated in disease progression. Nature biotechnology. 2011; 29: 742-749. http://dx.doi.org/10.1038/nbt.1914

[45] CHUNG S, NAKAGAWA H, UEMURA M, PIAO L, ASHIKAWA $\mathrm{K}$ et al. Association of a novel long non-coding RNA in 8q24 with prostate cancer susceptibility. Cancer science. 2011; 102: 245-252. http://dx.doi.org/10.1111/j.1349-7006 $.2010 .01737 . x$

[46] CUI ZL, REN SC, LU J, WANG FB, XU WD et al. The prostate cancer-up-regulated long noncoding RNA PlncRNA-1 modulates apoptosis and proliferation through reciprocal regulation of androgen receptor. Urol Oncol-Semin Ori. 2013; 31: 1117-1123. http://dx.doi.org/10.1016/j.urolonc.2011.11.030

[47] FERREIRA LB, PALUMBO A, DE MELLO KD, STERNBERG C, CAETANO MS et al. PCA3 noncoding RNA is involved in the control of prostate-cancer cell survival and modulates androgen receptor signaling. Bmc Cancer. 2012; 12. doi: Artn 507

[48] VAN DENDEREN BJW, THOMPSON EW. CANCER The to and fro of tumour spread. Nature. 2013; 493: 487-488. http:// dx.doi.org/10.1038/493487a 
[49] TAHIRA AC, KUBRUSLY MS, FARIA MF, DAZZANI B, FONSECA RS et al. Long noncoding intronic RNAs are differentially expressed in primary and metastatic pancreatic cancer. Mol Cancer. 2011; 10. doi: Artn 141

[50] GUPTA RA, SHAH N, WANG KC, KIM J, HORLINGS HM et al. Long non-coding RNA HOTAIR reprograms chromatin state to promote cancer metastasis. Nature. 2010; 464: 1071-1076. http://dx.doi.org/10.1038/nature08975

[51] JI P, DIEDERICHS S, WANG W, BOING S, METZGER R et al. MALAT-1, a novel noncoding RNA, and thymosin beta4 predict metastasis and survival in early-stage non-small cell lung cancer. Oncogene. 2003; 22: 8031-8041. http://dx.doi. org/10.1038/sj.onc. 1206928

[52] GUTSCHNER T, HAMMERLE M, EISSMANN M, HSU J, KIM Y et al. The Noncoding RNA MALAT1 Is a Critical Regulator of the Metastasis Phenotype of Lung Cancer Cells. Cancer Res. 2013; 73: 1180-1189. http://dx.doi.org/10.1158/00085472.CAN-12-2850

[53] YUAN JH, YANG F, WANG F, MA JZ, GUO YJ et al. A long noncoding RNA activated by TGF-beta promotes the invasion-metastasis cascade in hepatocellular carcinoma. Cancer cell. 2014; 25(5): 666-681. http://dx.doi.org/10.1016/j. ccr.2014.03.010

[54] LING H, SPIZZO R, ATLASI Y, NICOLOSO M, SHIMIZU $\mathrm{M}$ et al. CCAT2, a novel noncoding RNA mapping to 8q24, underlies metastatic progression and chromosomal instability in colon cancer. Genome Res. 2013; 23: 1446-1461. http:// dx.doi.org/10.1101/gr.152942.112

[55] YANG F, HUO XS, YUAN SX, ZHANG L, ZHOU WP et al. Repression of the long noncoding RNA-LET by histone deacetylase 3 contributes to hypoxia-mediated metastasis. Molecular cell. 2013; 49: 1083-1096. http://dx.doi. org/10.1016/j.molcel.2013.01.010

[56] LEE GL, DOBI A, SRIVASTAVA S. Prostate cancer: diagnostic performance of the PCA3 urine test. Nature reviews Urology. 2011; 8: 123-124. http://dx.doi.org/10.1038/nrurol.2011.10

[57] WANG XS, ZHANG Z, WANG HC, CAI JL, XU QW et al. Rapid identification of UCA1 as a very sensitive and specific unique marker for human bladder carcinoma. Clinical Cancer Research. 2006; 12: 4851-4858. http://dx.doi. org/10.1158/1078-0432.CCR-06-0134

[58] PANZITT K, TSCHERNATSCH MMO, GUELLY C, MOUSTAFA T, STRADNER $M$ et al. Characterization of HULC, a novel gene with striking up-regulation in hepatocellular carcinoma, as noncoding RNA. Gastroenterology. 2007; 132: 330-342. http://dx.doi.org/10.1053/j.gastro.2006.08.026

[59] LI J, CHEN Z, TIAN L, ZHOU C, HE MY et al. LncRNA profile study reveals a three-lncRNA signature associated with the survival of patients with oesophageal squamous cell carcinoma. Gut. 2014; 63: 1700-1710. http://dx.doi.org/10.1136/ gutjnl-2013-305806

[60] ZHU YY, YU M, LI ZH, KONG CZ, BI JB et al. ncRAN, a Newly Identified Long Noncoding RNA, Enhances Human Bladder Tumor Growth, Invasion, and Survival. Urology. 2011; 77. doi: ARTN 510.e1

[61] YANG Z, ZHOU L, WU LM, LAI MC, XIE HY et al. Overexpression of Long Non-coding RNA HOTAIR Predicts
Tumor Recurrence in Hepatocellular Carcinoma Patients Following Liver Transplantation. Annals of Surgical Oncology. 2011; 18: 1243-1250. http://dx.doi.org/10.1245/ s10434-011-1581-y

[62] DAVIS ME, ZUCKERMAN JE, CHOI CHJ, SELIGSON D, TOLCHER A et al. Evidence of RNAi in humans from systemically administered siRNA via targeted nanoparticles. Nature. 2010; 464: 1067-U1140. http://dx.doi.org/10.1038/ nature 08956

[63] XIE CY, YUAN J, LI H, LI M, ZHAO GG et al. NONCODEv4: exploring the world of long non-coding RNA genes. Nucleic Acids Res. 2014; 42(D1): D98-D103. http://dx.doi. org/10.1093/nar/gkt1222

[64] VOLDERS PJ, VERHEGGEN K, MENSCHAERT G, VANDEPOELE K, MARTENS L et al. An update on LNCipedia: a database for annotated human lncRNA sequences. Nucleic acids research. 2014. http://dx.doi.org/10.1093/nar/ gku1060

[65] QUEK XC, THOMSON DW, MAAG JL, BARTONICEK N, SIGNAL B et al. lncRNAdb v2.0: expanding the reference database for functional long noncoding RNAs. Nucleic acids research. 2014. http://dx.doi.org/10.1093/nar/gku988

[66] LI JH, LIU S, ZHOU H, QU LH, YANG JH. starBase v2.0: decoding miRNA-ceRNA, miRNA-ncRNA and protein-RNA interaction networks from large-scale CLIP-Seq data. Nucleic acids research. 2014; 42: D92-97. http://dx.doi.org/10.1093/ nar/gkt1248

[67] PARASKEVOPOULOU MD, GEORGAKILAS G, KOSTOULAS N, RECZKO M, MARAGKAKIS $M$ et al. DIANA-LncBase: experimentally verified and computationally predicted microRNA targets on long non-coding RNAs. Nucleic Acids Res. 2013; 41: D239-D245. http://dx.doi. org/10.1093/nar/gks1246

[68] CHEN G, WANG ZY, WANG DQ, QIU CX, LIU MX et al. LncRNADisease: a database for long-non-coding RNAassociated diseases. Nucleic Acids Res. 2013; 41: D983-D986. http://dx.doi.org/10.1093/nar/gks1099

[69] NING SW, ZHAO ZXL, YE JR, WANG P, ZHI H et al. LincSNP: a database of linking disease-associated SNPs to human large intergenic non-coding RNAs. Bmc Bioinformatics. 2014; 15. doi: Artn 152

[70] HUANG J, ZHOU N, WATABE K, LU Z, WU F et al. Long non-coding RNA UCA1 promotes breast tumor growth by suppression of p27 (Kip1). Cell death \& disease. 2014; 5. doi: ARTN e1008

[71] KINO T, HURT DE, ICHIJO T, NADER N, CHROUSOS GP. Noncoding RNA Gas5 Is a Growth Arrest- and StarvationAssociated Repressor of the Glucocorticoid Receptor. Sci Signal. 2010; 3. doi: ARTN ra8

[72] ZHANG X, GEJMAN R, MAHTA A, ZHONG Y, RICE KA et al. Maternally Expressed Gene 3, an Imprinted Noncoding RNA Gene, Is Associated with Meningioma Pathogenesis and Progression. C

[73] YOON JH, ABDELMOHSEN K, SRIKANTAN S, YANG XL, MARTINDALE JL et al. LincRNA-p21 Suppresses Target mRNA Translation. Mol Cell. 2012; 47: 648-655. http://dx.doi. org/10.1016/j.molcel.2012.06.027 